\title{
Titanium asa Biomaterial For Dental ImplantsandIts Corrosion Rate- An Animal Study
}

\author{
Dr. R S Gugwad, Dr. Savita Chakote*, DrSharanbasappa CNagaral, DrGoslaShrinivas \\ Reddy, Director \\ Professor and HOD, Dept of DentistryBidar Institute of Medical Sciences. Bidar- Karnataka state \\ Associate Professor, Department Of Dentistry,Bidar Institute of Medical Sciences.Bidar-Karnataka state, \\ India. \\ Professor, Dept of ProsthodonticsAl badar dental college, Gulbarga, Karnataka \\ GSR institute of cranio-maxillofacial plastic surgery,Hyderabad.AP \\ *Corresponding author: *Dr. Savita chakote
}

\begin{abstract}
Titanium (Ti) and its alloys have been demonstrated to have considerablesuccess in various surgical procedures including orthopedic, maxillofacial, as a result of their excellent biocompatibility and resistance to corrosion. Titanium is therefore being preferred worldwide. The aim of this prospective and randomized comparative study is to test the biocompatibility and corrosion rate of the pure titanium implant and 316 stainless steel implants material. An experimental study in rabbits was done to compare the biocompatibility and corrosion rate around the metal implants specimens. The experimental animals were sacrificed at 2,4,8,12, and 16 weeks from the date of implantation. The histopathological examination of the animals sacrificed at 16 weeks demonstrates the excellent biocompatibility and low corrosion rate in titanium implant compared to stainless steel implants.
\end{abstract}

Key Words:Pure Titanium implants, Osseointegration, Biocompatibility Corrosion Rate, Histopathological

\section{Introduction}

The first requirement for any material to be placed in the human body is that it should be biocompatible and not cause any adverse reaction in the body ${ }^{1}$. The material must withstand the body environment and should not degrade to a point that it cannot function in the body as intended ${ }^{2}$. Corrosion of metal implants is critical because it can adversely affect the biocompatibility and mechanical properties. The materials used should not cause any adverse biological reaction in the body and, simultaneously, they must be stable retaining their function properties. Corrosion and surface oxide film dissolution are the two mechanisms which introduce additional ions into the body ${ }^{3,4}$. Extensive release of ions from prosthesis can result in adverse biological reactions leading to mechanical failure of the device. For example, release of nickel ion from 316LVM implant alloys may cause allergic effects in some patients.

Titanium (Ti) and its alloys have been demonstrated to have considerable success in various surgical procedures including success in various surgical procedures including orthopaedic, maxillofacial, and cardiovascular surgery. Pure titanium and titanium alloys are the most frequently used materials for osseoinegrated dental and orthopaedic implants because of their biocompatibility ${ }^{5,6,7,8,19}$.

The aim of the present study was to compare the biocompatibility and corrosion rate of titanium and stainless steel. We evaluated histologically the biological effect of corrosion and osseointigration in the periimplant site in rabbit's femur. The results will contribute clinically useful data on the biocompatibility of metal implants used in osteosynthesis in the body.

\section{Material and Methods}

Material used in this study were titanium and stainless steel implant, which were cut into small pieces to suit the design of the experiment study in rabbits as an implant material and as comparative control stainless steel monocorticalminiplates which were also cut into small pieces to suit the design. The animals used in this study were white New Zealand rabbits of 1 year and six months old, weighing 2-3 kg. In all, 12 healthy rabbits were selected for the study. Institutional ethical committee clearance was taken for the animal study.

\section{Implants}

The implants used were in the form of plate with two holes, measuring $5 \mathrm{~mm}$ in length and $1.5 \mathrm{~mm}$ thick and $2 \mathrm{~mm}$ diameter of screw. 
In this study a total of 10 implants were used, out of which 5 implants used were pure titanium and the rest 5 implants were stainless steel having similar shape and dimension as pure titanium implant material that were used as control group.

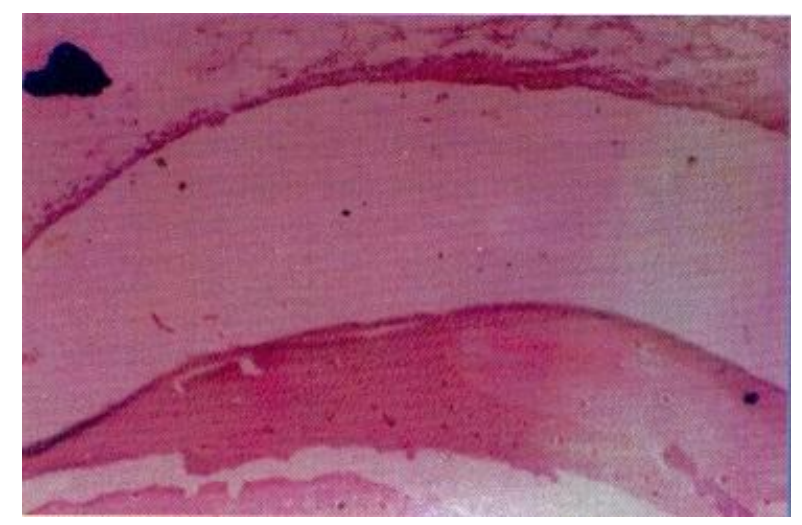

Fig. (1):Photomicrograph (80X) of controlled specimen without any implant material implanted, revealing no inflammatory exudates, no fibroblasts, normal mature bone no osteoblatic or osteoclastic activity

\section{Surgical Procedure:}

Under aseptic precautions, the animals were anaesthetized with ketamin $1 \mathrm{mg} / \mathrm{kg}$ body weight intramuscularly. Once the animals were anaesthetized an incision of $3 \mathrm{~cm}$ was placed on the right and left aspect of the femoral region titanium plate was implanted and the same procedure was carried out on the left leg and then the comparative control stainless plate was implanted.

The same procedure was carried out on all the 12 rabbits; one was used as control animal in which the same procedure was carried out expect that no implant material was placed. In order to study the soft tissue and bony changes around the implant and the corrosion of implant, the animals were divided into 2 groups, Group 1 was histological study and Group 2 was corrosion study. In each group the animals were tagged and marked A B C D E and F.

\section{Histological study}

In order to study the soft and hard tissue reaction of implanted materials the Group 1 and 2 animals were sacrificed in the following manner:

Group A-2 weeks, Group B-4 weeks, Group C-8 weeks, Group D-12 weeks, Group E\&F - 16 weeks.

For histological study $3 \mathrm{~cm}$ autopsy of soft and hard tissues around the implanted were obtained and processed by haematoxylin and eosin stain.

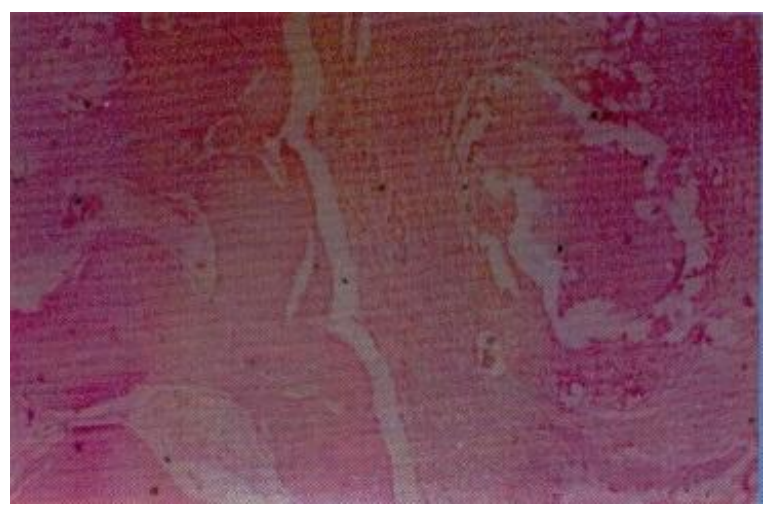

Fig.(2): Photomicrograph (80X) of titanium specimen implanted site after 2 weeks showing both acute and chronic inflammatory cells, Small areas of bone necrosis with intervening fibroblastas are seen, around the implanted site. 
Corrosion study

The Mills per year method was used in order to study the corrosive properties of the titanium and the comparative control stainless steel.

Mills per year $(\mathrm{M} / \mathrm{Y})=534 \mathrm{w} / \mathrm{DTA}$

$\mathrm{W}=$ Weight loss ( preimplantation wt.-post implantation wt. of the material in $\mathrm{mg}$ )

$\mathrm{D}=$ Density of material in $\mathrm{gm} / \mathrm{cm}$ cube.

$\mathrm{T}=$ Time of exposure in hours.

$\mathrm{A}=$ area of specimen in sq. inches.

The pre and post implantation weight was measured by using the METTLER signal pan electronic balance.

\section{Results}

No immediate or intermediate postoperative complications were observed in any of the control or experimental animals.

\section{Histologic Observation:}

Histologic study was carried out over a period of $2,4,8,12$, and 16 weeks to observe the soft tissue bone lining response towards implant site. Group A revealed both acute and chronic inflammation and no evidence of osteoblast formation. But in Titanium specimen intervening fibroblasts were present along with inflammatory cells.

Group B revealed osteoblast cell proliferation around implant site, no inflammatory cells and bone necrosis were seen. In $316 \mathrm{~L}$ stainless steel specimen no sign of osteoblast activity and chronic inflammatory area.

Group C revealed new ordered bone towards the implanted site, no signs of bone necrosis and inflammatory cells. In $316 \mathrm{~L}$ stainless steel specimen showed thick fibrous capsule around implanted site and new bone formation at the neighboring site of implanted area.

Group D revealed presence of osteogenesis of bone with osteoblasts lined up towards the implant site. Pre existing mature bone was seen adjacent to ordered bone. In $316 \mathrm{~L}$ stainless steel specimen compact collagen tissue around the bone implant interface was seen. No significant osteoblastic cell formation was found.

Group E revealed osteoblastic cell proliferation towards bone implant interface and brownish black pigmented particles in the intercellular matrix. In $316 \mathrm{~L}$ stainless steel specimen showed presence of layer of osteoblastic cell proliferation towards the bone implant interface. No sign of young bone formation,

Group $\mathrm{F}$ was controlled specimen without any implant materials in them. Histologic examination showed no exudates, fibroblasts, normal mature bone with no osteoblastic or osteoclastic activity.

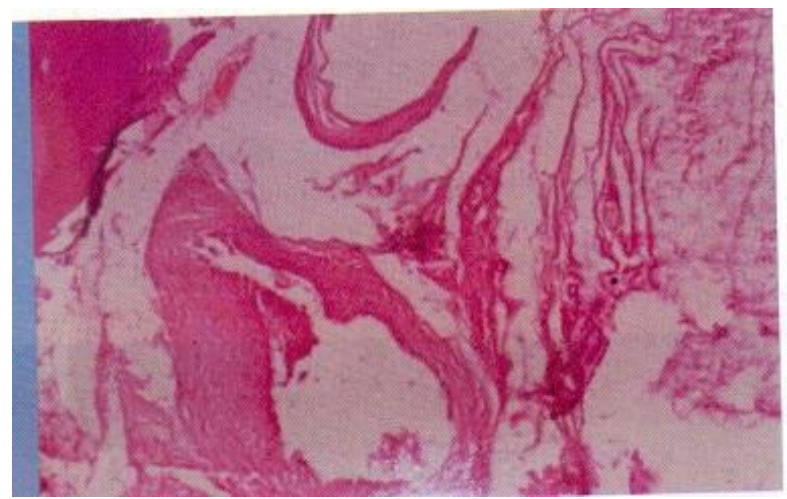

Fig. (3): Photomicrograph (80X) of $316 \mathrm{~L}$ stainless steel specimen implanted site after 2 weeks showing the presence of dense chronic inflammatory infiltrate in the bony interstices 


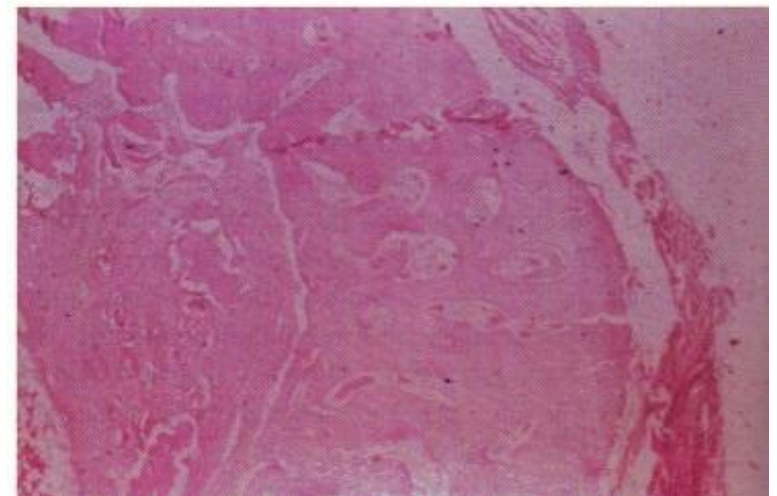

Fig.(4):Photography (80X) of titanium specimen implanted site after 8 weeks showing the presenceof few layers of collagen tissue around the implant site. Osteoblastic cell proliferation is seen within the adjacent normal bone there is no signs of bone necrosis and inflammatory cells

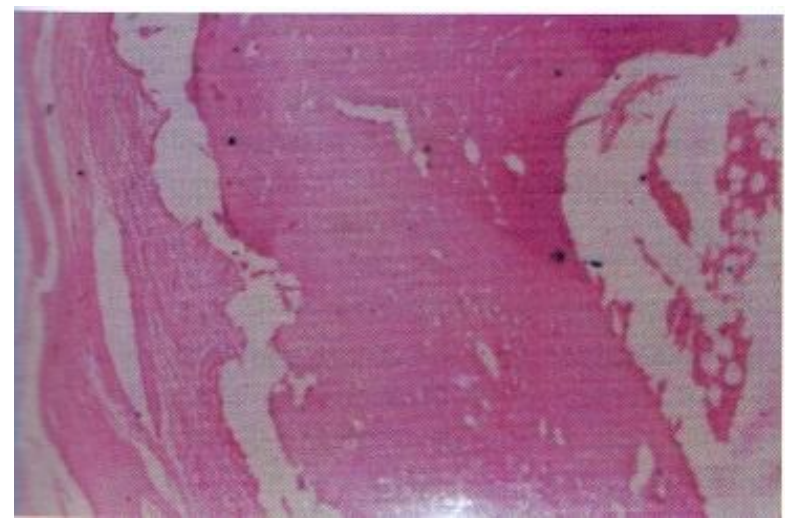

Fig.(5): Photomicrograph (80X) of 316L stainless specimen implanted site after 8 weeks, showing thick fibrous capsule around the implanted site, with new bone formation at the neighboring site of the implantedarea. Marked dilated blood vessels noticed in the marrow space, no inflammatory cells or exudates is seen

\section{Corrosion Study:}

The Rate of corrosion of Titanium implant material and 316 LO stainless steel implant material was measured by Fontana's weight loss method,

$\mathrm{M} / \mathrm{y}=\underline{534 x \text { loss of weight implant }}$

Density of metal X time of exposure X surface of implant

According to the criteria given by Mars G. Fontana for estimation of corrosion rate by weight loss method, any metal less than 1 MPY is considered as outstanding biocompatible material. On inferring the observation for 16 weeks it was found that both the metals are outstandingly biocompatible materials, but titanium $(0.088 \mathrm{M} / \mathrm{y})$ when compared with stainless steel ( $0.13 \mathrm{M} / \mathrm{y}$ ) has undergone very less corrosion. 


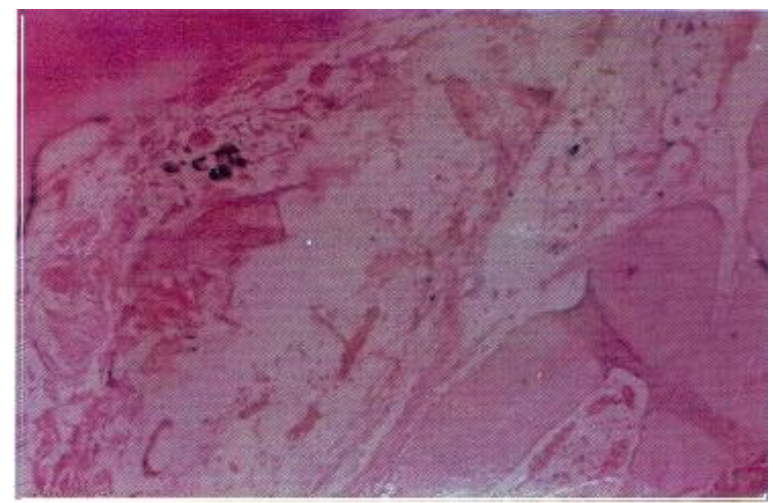

Fig.(6): Photomicrograph (80X) of titanium specimen implanted site after 16 weeks, showing the bone implant interface, non Lamellar bone is seen adjacent to the implant site, there is no collagen tissue, the pre- existing mature bone is seen adjacent to the non lamellar bone.

\section{Discussion}

Histologic studies substantiate and authenticate clinical experience in dentistry as well as in medicine. Most of the opportunities for studying the effect of dental implant on living human tissue have been provided by failing implants. Only a few studies have been done on site bearing successful implants.

The earliest histological studies of inert metal screws were reported in 1949 by Alvin Stock and MooesStrock ${ }^{15}$.

The soft tissue and hard tissue around implants shoed variation in tissue reaction depending on the biomaterials used, design of the implants and surgical approach. The corrosion resistance, biocompatibility, adequate strength, fatigue are requirements for ideal implant material ${ }^{11,14}$.

Metallic implants find wide application in the field of implantalogy in recent years. These are major reports to substantiate the soft tissue biocompatibility of pure titanium ${ }^{7,8,15}$.

In the present study an attempt has been made to assess the biocompatibility and corrosion rate of pure titanium and stainless steel implant materials.

Moberge et al $^{16,17}$ analyzed the tissue reaction around implanted material. He found out that visible pigmentation in soft tissue was covering titanium miniplates. Even in our study, brown black pigmented spots near the implanted site were noticed and histologically these pigmentation spots were confirmed.

According to Rosenberg et $\mathbf{a l}^{\mathbf{1 8}}$ these pigmentations are due to deposition of titanium oxide. On the contrary no pigmentation was found around the $316 \mathrm{~L}$ stainless steel implant.

An histological observation at 2 weeks revealed the presence of acute and chronic inflammatory cells and small area of necrosis in both the groups but in titanium implants presence of intervening fibroblasts was seen.

A. R. Erikson et al suggested that these necrotic zones were insignificant ads the bone may remodel slowly after few weeks of implantation ${ }^{5}$.

Branemark et al reported that healing of bone differed from healing of other kinds of tissue ${ }^{6,7,19}$.

The histological observation at 4 weeks revealed the absence of bone necrosis around the indigenously produced pure titanium and stainless steel alloy test specimens.

The most remarkable feature was the formation of obsteoblasts towards the titanium site. 8 weeks observation has shown the presence of few layers of collagen tissue osteogenesis of the bone with osteoblasts around the titanium implant, whereas the stainless steel implant had shown the presence of fibrous capsule surrounding it with new bone formation at the neighboring sites.

The observation can be substantiated with the earliest findings of W.B. Weiss et al, who reported that Baboon studies have shown the successful formation of osteoblasts and collagen tissue around the pure titanium implants at 8 weeks after implantation.

Histologic observation at 12 weeks revealed the formation of young bone around titanium implant. This could be substantiated with the finding of Johansson et al and P.I. Branemark et al.

In contrary to the osteoblastic activity around the titanium implant, with total acceptance of reaction.Branemark P.I., Alberktson et al reported the presence of direct bone to implant interface contact at 
the electronic microscopic level. Histologic observation also showed osseointegration which clearly suggestive of excellent compatibility of implant material.

Corrosion Study:

Animal studies of Baboons with titanium alloy implants have been shown significant time dependent accumulation of aluminium and titanium in the lungs. Rosenberg has reviewed regarding the accumulation of titanium particles in regional lymph nodes. In our study we have found brownish red pigmented particles in the intercellular matrix on histologic examination, which could be due to titanium oxide particles during implantation procedure.

Van Orden emphasized the relationship of corrosion fatigue in implants occurring when passive film is broken due to machining defects, microscopic cracks and porosity in the material.

Lemonshas pointed out that the shear movement of the soft tissue interface could potentially result in the release of metallic products of even in the most inert implant material. Still others have emphasized the needs to derive more accurate understanding of the rate of metal ion release from implants.

In our study we were able to justify the two justification for corrosion by Mars G. Fontana ${ }^{23}$ by evaluation and selection of titanium implant material to test its corrosion rate in vivo for a specified time of 16 weeks and titanium was compared with stainless steel implant material. Later, both the materials were studies for corrosion rate as a part to test the biocompatibility of titanium and stainless steel in vivo.

In our study, it was very much noted that titanium had very less corrosion rate in comparison with $316 \mathrm{~L}$ stainless steel, due to the high inertness and passive nature of titanium, as explained by Gregary R. Parr et al $^{24}$.

It was concluded that:

\section{Conclusion}

1. There was ample evidence indicating the bio-compatibility of indigenously produced pure titanium implant material.

2. There was no variation in tissue reaction to both indigenously prepared titanium and $316 \mathrm{~L}$ stainless steel implant materials.

3. New ordered bone was formed around indigenously produced pure titanium implant material over a period of 16 weeks after implantation, suggestive of osseointegration around bone implant interface.

As this study was done for short periods using only light microscop, further studies regarding the bone and titanium interface using transelectronic microscope have to be done. The cytotoxicity and mutagenecity also have to be assessed using cell culture studies. This kind of multicentric clinical trial will help in evaluating the general bio-compatibility of indigenously produced pure titanium implant material.

\section{References}

[1]. A.C Fraker, Corrosion, ASM Handbook, ASM International, Vol. 13, pp . 1324-1335, 1992

[2]. M. Niinomi, Mat. Sci. Eng. A243 (1998) 231-236 J. R. Davis, Handbook of materials for medical devices, ASM international, 2003

[3]. Gurappa, Mat. Charact. 49(2002) 73-79.

[4]. Abramson S, Alexander H, Best S, etalclasses of materials used in medicine. In: Ratner B, Hoffman A, Schoen F, Lemons J, eds: Biomaterials science. An introduction to materials in medicine. San Diego: Elsevier Academic press 2004: 67-233

[5]. Adell R, Ericksson B, Lekholm V, Branemark PI, Jemt t. A long-term follow up study of osseointegrated implants in the treatment of the totally edentulous jaw. Int J oral Maxillofac Implants 1990: 5: 347-359.

[6]. Albrektsson T. A multcenter report on osseeointegrated oral implants. J prosthet Dent 1988: 60:75-84

[7]. Branemark P.I., Alberktson T. 1981: Osseointegrated titanium implants, requirements for ensuring a long lasting direct bone to implant anchorage in man. Actaorthopaedicascandinavica 52(2): 155-70, 1981

[8]. Branemark PJ.; osseointegration and its experimental background J. Prosthetic dent 1983, 50: 399-410

[9]. Laing P.G., Ferguson A.B., Hodge E.S.: Tissue reaction in rabbit muscle exposed to metallic implants J. of Biomed Mater. Res. 1: 135,1967

[10]. Linderberg L.R., Linder L., Johnell D.: Reactions in rat gluteal muscle to titanium implants, biomaterials 1988 Nov. 9(6) 547-9.

[11]. Homsy C.A., Kent J.N., Hinds E.C.: Materials for oral implantology biological and fuctional criteria J. Am. Dent. Assoc. 86:817, 1973.

[12]. Head W.C., Bauk D.J., Emerson RH. Jr.: Titanium as the choice for comintlers femoral components in total hip orthoplastyclini. Orthop. 1995, Feb(311) 85490

[13]. Leonard I. Linkow: theories and techiniques of oral implantology. Evolution of dental implants. The C.V Mosby company saint Lois Vol. 1, Pg. 137-139, 1970

[14]. Langlais F.: New biomaterials in orthopedics Press Med. 14(26): 1424-28, 1985.

[15]. 15. Jack Lemons, Joseph Natiella: Biomaterials biocompatibility and peri implant considerations dental clinics of North America 30(1): 3-23, 1986 
[16]. Moberge L.E., Nordensama et al.: Metal release from plates used in jaw fractures treatment a pilot study Int.J. Oral MaxilloFaci. Surg. 18:311-314, 1989.17.

[17]. Morberg P. and Albrektson T.: Removal torque for bone cement and titanium screws implanted in rabbits ActaOrthop. Scand. 1991 Dec., 62(6): 554-6.

[18]. Rosenberg A., Garty K.W., H.F. sailer: should titanium miniplates be removed after bone healing is complete? Int.J.OralMaxillo facial surgery 22: 185-188, 1993.

[19]. Branemark P.I., Zarb, Alberktson t.: Tissue integrated Prosthsis, osseointegration in clinical dentistry qui'ntersence publishing co. Inc. Chicago, Illinois First Edition Pg. 108-113, 1983

[20]. Weiss W.B., Rastoker: Development of a new endosseous dental implant part I animal studies J. Pros. Dent 46: 646- 651, 1981.

[21]. Van Orden A.: Corrosive response of the interface tissue to $316 \mathrm{~L}$ stainless steel titaniumunbased alloys and chrome based alloys In. Mckiriney R., Lemons T., eds. The dental implant Littleton, MA, PSG publishing, 1985, 17.

[22]. Lemons J.: corrosion and biodegradation. In. von Recum A., ed. Handbook of biomaterials evaluation. Scientific, technical and clinical testing of implant materials, New York. Macmillan Publishing Co., 1986, 109.

[23]. Mars g. Fontana: Text book of corrosion engineering 1985, R 142-162.

[24]. Gregary R. Parr; Kirk Gardner L.: Titanium the mystery metal of implant dentistry dental materials aspect J. Pros. Dent. 54: 410$414,1985$.

Dr. R S Gugwad. "Titanium As A Biomaterial For Dental Implants andIts Corrosion Rate- An Animal Study." IOSR Journal of Dental and Medical Sciences (IOSR-JDMS) 16.7 (2017): 4045 . 